\title{
Ciencia, sabiduría y sociedad
}

\author{
Vicente Pelechano \\ Universidad de La Laguna (Tenerife, España)
}

RESUMEN

La crisis que padecemos parece que es mucho más que económica y formaría parte del "síndrome milenarista" que tiende a presentarse a finales de siglo-milenio y parece más profunda y extensa que su referencia económica. Se sugieren campos de cambio profundo en la manera de ser y proceder del ser humano respecto a la sociedad, los valores, las "religiones laicas" (partidos políticos, la percepción de la ciencia y el mercado, como ejemplos) y se señalan algunos de los efectos negativos de la globalización. Se denuncia una crisis en la valoración de los regímenes democráticos actuales, así como un fracaso en la promoción de la sociedad de la competitividad y la eficacia. Finalmente, se propone recuperar a la psicología como una de las "ciencias del hombre", en la que debe tener su lugar la sabiduría, como promoción de un sistema funcional de convivencia más humano y satisfactorio.

Palabras clave: sabiduría y mundo social, roles de ciencia en mundo social, cambio de valores, nuevas religiones, impacto de globalización, sabiduría como uso de conocimiento, sabiduría individual y social.

\section{ABSTRACT}

The contemporary crisis is more than an economic problem and perhaps it is part of the "millennium syndrome", with severe changes in the role and meaning of science, the laicism religions (political parties, a specific perception of science, the money market) and the globalization effects on citizens. There is a critical and depressive perception of the democracy system as solution of the contemporary problems and it seems true a failure in the belief of the society of competition and efficacy. One suggests that psychology as a "science of the human being" and the wisdom has an important place in the near future.

Keywords: wisdom and social world, science roles in social world, change of values, laicism religions, globalization impact, wisdom as use of knowledge, individual and social wisdom. 


\section{a. Una nota acerca de la ciencia, los valo-} res y la sociedad.

Dos de las cuestiones apenas tratadas en la idea de ciencia, y cuando han sido tratadas se han presentado como posiciones incompatibles y radicales, se refieren a la delimitación de lo que significa ciencia y su ámbito de actuación, por un lado y, por otro, a las relaciones entre la ciencia y el mundo social, lo que incluye el papel que desempeñan los valores (en buena medida, el papel que desempeñan los componentes no cognitivos) en la epistemología y actividad científica'.

Por lo que se refiere a la primera cuestión, por una parte se defiende la ciencia como una actividad que se genera y agota en sí misma, lo que implica un conjunto de actividades que comienzan con la acción científica y terminan en ella, serían "auto-inclusivas", autocontenidas y referidas a esa actividad que, por otro lado, se concibe como acciones realizadas al margen e independientemente del mundo social. En buena cuenta recogería una manera de entender la ciencia cuando ésta era cultivada por científicos preocupados por sus propias hipótesis y teorías, que se entendían, en gran parte, independientes del mundo cotidiano (y cuando se referían a ese mundo, se ocupaban de explicar la realidad física, pero no de modificarla). En la posición opuesta se encuentra la

1 Desde un análisis, posiblemente más radical, el problema no se restringe a los valores sino que se puede generalizar a cualquier elemento "no cognitivo" de la actividad científica, soslayando que la afectividad forma parte esencial de la actividad científica y del científico. El papel que desempeña la afectividad en la elaboración de la epistemología científica ni siquiera se ha insinuado; y el papel que desempeña en la asignación de hechos relevantes o no, de su posible interacción percibida y de su influencia en la aceptación de novedades metodológicas y conceptuales, tampoco ha sido tratado más que, en todo caso, como "deformaciones perceptuales" de la realidad. Y el autor piensa que son mucho más que eso. concepción de la ciencia como una actividad más dentro del resto de actividades sociales, que incide sobre estas actividades $\mathrm{y}$, por lo tanto, las actividades científicas se entienden, en gran medida, embebidas en la matriz de conceptos que forman el mundo social. Esta manera de entender la ciencia ha ido creciendo en importancia hasta el punto que, en nuestros días, es realmente imposible de entender el mundo en que vivimos, sin incorporar la ciencia como uno de los componentes y actividades básicas a las que se hace responsable hasta del bienestar económico y social.

Por lo que se refiere a la segunda cuestión (el papel desempeñado por la ciencia en la estructura, dinámica y bienestar social), asimismo pueden diferenciarse dos posiciones. En una parte se encuentran los partidarios de una "ciencia neutral", en la que se defiende que no existen compromisos de valor en lo que se refiere a su actividad y sus resultados $y$, precisamente por ello, la ciencia resulta "objetiva". En la otra, se encuentran los partidarios de la ciencia que, como toda actividad humana, presenta compromisos con los valores y, por ello, los resultados tanto como las acciones deberían tomar en consideración esos valores a la hora de la correcta y adecuada interpretación de los resultados, así como de su aplicación e incluso deberían incorporarse en la definición de lo que sea ciencia.

La primera posición, básicamente mecanicista, defiende que la ciencia es una actividad "des-encantada" (Kendler, 1999) caracterizada por una epistemología empirista, en la que los resultados dan o quitan la razón y, en el caso de haberse diseñado y realizados los estudios 
de manera correcta (de acuerdo con la metodología científica) los resultados no poseen valores, son básicamente descriptivos de lo que sucede, pero de ellos no debe deducirse lo que se debería hacer (esto es, desde la ciencia no se justificaría ningún tipo de decisión de política social, educativa o sanitaria) y por ello, la ciencia y la ética tanto como la política, son parcelas independientes y como tales deben mantenerse). De esta manera, cuestiones tales como la permisividad acerca del aborto, el bilingüismo en educación o la admisión o no de ciertos movimientos religiosos que prohíben la puesta en práctica de ciertas prácticas sanitarias como la transfusión, no se deben justificar o prohibir en función de resultados científicos sino en función de la presencia de una diversidad de códigos morales dentro del mundo social y de sus respectivos compromisos con distintos planteamientos ideológicos ${ }^{2}$.

Este posicionamiento resulta conveniente desde un punto de vista "higiénico" y referido básicamente a las ciencias "naturales" en la medida en que defiende una manera ortodoxa y cerrada sobre sí misma de la actividad científica y encontraría su mayor justificación de ser en las investigaciones y estudios "básicos" de esas ciencias naturales (aunque incluso en ellos se asignan valores a las acciones científicas y a la metodología que se debe utilizar). La tradición de pensamiento que se encuentra a la base de

2 Esta afirmación llevaría consigo la aceptación de que la ética y la moral no son susceptibles de estudio científico. Se acepta la pluralidad de éticas dentro del mundo social (sin especificación de límites) y se asumiría, en líneas generales, que dentro de esquemas de pensamiento muy amplios, todas ellas poseen el mismo valor, aunque nada se asume acerca de los criterios y modos de validación, que, en todo caso, no serían "científicos", en la medida en que no se podrían derivar de los resultados alcanzados lo que se debería hacer (que es típico de la ética). esta posición es empirista y deseosa de aislar de la actividad científica todo aquello que no está definido como científico, con la posibilidad de generar un modelo de funcionamiento científico del mundo físico al margen de la actividad humana social (independiente de los movimientos religiosos, tanto como sociales).

Esta idea de ciencia, que ha estado presente durante muchos años incluso dentro del mundo académico en su esfuerzo por mantener el "purismo científico" presenta la ventaja de promover la ciencia como conocimiento "puro", aunque en el modo de entender el conocimiento verdadero y las maneras de contrastar las hipótesis planteadas se encuentran presentes valores tales como la mayor importancia atribuida a los resultados empíricos que a los análisis racionales, la necesidad de poner a prueba diferentes hipótesis acerca de un mismo fenómeno $y$, en definitiva, la adscripción del científico al método hipotético-deductivo, propio de la ciencia y su conversión en el patrón de comparación y validación de todo resulta$\mathrm{do}^{3}$. Y junto a estos "valores cognitivos", existen otros de corte ético y que se corresponden con la correcta extracción de los datos, de análisis de resultados y de interpretación adecuada de los mismos. Y, por otra parte, en bastantes ocasiones, los descubrimientos científicos generan problemas de difusión y aplicación social, como sucedió con la energía atómica y sus

3 Curiosamente, la metodología científica se refiere a la manera de contrastar hipótesis, pero ha dejado de lado de manera radical la generación de hipótesis (la creatividad científica). Y el asunto no es baladí en la medida en que sin creatividad científica, sin generación de hipótesis, resulta imposible entender el progreso científico. El método científico sirve para confirmar o desmentir las hipótesis y modelos conocidos (previamente generados), pero no para crear nuevos conocimientos. Mientras tenemos cánones para "valorar" los resultados experimentales, no los tenemos para "valorar" la creatividad científica. 
desarrollos tanto en el campo bélico como en sus aplicaciones para la generación de energía o para la terapéutica del cáncer ${ }^{4}$.

El caso de las ciencias "sociales", entre las que se encuentra la psicología se presenta como algo distinto. De hecho, estas ciencias sociales que se plasman académicamente a partir de los siglos XVIII y XIX (psicología, sociología, economía) se gestan a partir de dos tipos de influencias: por un lado, el mimetismo de las ciencias naturales (física y biología) y su pasión por lograr conocimiento objetivo, susceptible de ser validado con procedimientos claros y "científicos", pero, por otro lado, desde la Baja Edad Media han estado apareciendo autores que intentan generar unas "ciencias del hombre" laicas, con nombres tan representativos como Vico, Locke, Hume, Montesquieu, Hartley, Bentham y el movimiento de la llustración en general, cuyos objetivos principales son no solamente el logro de conocimiento objetivo (entendido asimismo como conocimiento científico) sino también el logro de la felicidad y el bienestar personal (el empirismo inglés se encuentra en esta posición, pero también el utilitarismo posterior y los movimientos positivistas y materialistas). Y este objetivo implica necesariamente la introducción de los valores y sistemas de valores dentro de la actividad científica.

Lo cual, por otra parte, tampoco resulta tan novedoso. Ya en la Grecia clásica, los conoci-

4 No deja de resultar un tanto difícil de explicar que mientras poco después del final de la Segunda Guerra del siglo XX, un considerable volumen de físicos nucleares discutieron los problemas sociales de las aplicaciones realizadas hasta ese momento de la energía atómica, ninguna voz de la psicología occidental se ocupó de plantear y airear esos problemas. Problemas que, entre otras cosas, habían provocado la muerte de medio millón de personas en Japón. mientos científicos fueron aplicados al diseño de máquinas y de instrumentos de defensa del puerto de El Pireo en Atenas y descubrimientos científicos "naturales" como la pólvora o la dinamita, así como la aviación, la energía atómica y el vuelo dirigido modificaron sustancialmente las estrategias de guerra (que son, básicamente, aspectos de funcionamiento social más o menos esencial, hasta ahora).

La cuestión no es si se han aplicado o no los conocimientos de la ciencia al mundo social, sino si ello resulta un aspecto inherente y definitorio de la propia actividad científica. Psicológicamente, toda percepción y/o acción psicológica lleva implícito un juicio de valor (bueno/malo, agradable/desagradable por ejemplo), como parte de la apreciación de la realidad; otra cosa es que ello sea o no consciente y que su "justificación" sea o no adecuada. Tiende a convertirse en un proceso automático no consciente, que puede ser llamado a nivel de conciencia con una acción cuyo objetivo sea hacerlo consciente. De la misma manera que el estado de nuestros órganos internos no es un fenómeno consciente en la mayor parte de la vida, pero que se convierte en consciente en algún caso, si comienzan a existir anomalías y en otros, cuando las anomalías ya son considerables.

Una segunda cuestión conectada con lo que acaba de comentarse se refiere a si los resultados de la ciencia pueden ser una plataforma para la toma de decisiones sobre problemas físicos, personales y sociales (si puede inspirar o no decisiones políticas de acción). Incluso en el caso de la concepción de "ciencia neutral" la ciencia puede utilizarse para valorar el re- 
sultado de leyes o decisiones que se plasman en acciones, y de hecho debería ser utilizada para ello, y no solamente con un tipo de estudios sino de varios, de tantos como aspectos relevantes deban ser valorados (por ejemplo, resultados de una u otra ley de educación, o sus modificaciones; efectos de cambio climático). En el caso de la ciencia como actividad con reconocimiento de existencia de sistema de valores en esa actividad, no solamente resulta conveniente, sino muy recomendable asentar decisiones y cambio de decisiones basadas en una concepción amplia de la ciencia en el mundo de la política social y para ello se debe entender la actividad y resultados científicos como provisionales y debe mantenerse una actitud de apertura en el análisis de los problemas y de las múltiples variables relevantes que inciden en los fenómenos. La evaluación y la valoración provisional de resultados permiten la reorientación de aquellas parcelas que no están funcionando de manera adecuada. Al igual que el ser humano es histórico, la ciencia lo es también y frente a las concepciones convencionales de relaciones causa-efecto, se deben tomar en consideración las interacciones entre variables y la co-determinación de los fenómenos mientras éstos suceden. Y ello implica que las decisiones sociales, al igual que los resultados, grupos sociales y políticas poseen una valor temporal y provisorio; y que deberían modificarse porque inciden sobre los resultados a la vez que influyen sobre las decisiones que se deban tomar. La idea de resultados permanentes e inmodificables conectados a decisiones en ciencia social debería ser desterrada mientras exista desconocimiento de los parámetros y variables relevantes que determinan la aparición y dinámica de los fenómenos que se estudian.

La actividad de toda ciencia se lleva a cabo en una matriz social e histórica y resulta imposible salirse de ella. Todo científico vive en un tiempo histórico dado y en una sociedad concreta, que le permiten hacer, decir y pensar unas cosas y no otras y que influyen su pensar científico de maneras distintas. Los científicos no necesariamente son esclavos de esas matrices sociales, sino que, como creadores de ciencia, en alguna ocasión, por saltarse algunas de esas constricciones han sido condenados a morir en la hoguera, en otros casos, encerrados y en otros, finalmente, desterrados, porque han sido percibidos como agitadores sociales, revolucionarios o delincuentes.

Esta posición de inclusión de los valores dentro del pensamiento científico (lo que permitiría, entre otras cosas, prescripciones acerca de decisiones de política educativa, sanitaria y social, en general) es calificada por Kendler (1999) como "ciencia encantada", la hace depender de la psicología de la Gestalt en el caso de las escuelas psicológicas clásicas y la hace responsable de parte de la justificación de posicionamientos sociales antidemocráticos como el nazismo. Un elemento crucial en este discurso es la misma idea de "Gestalt", que es algo más que la suma de sus partes constituyentes, que esa percepción de Gestalten incluye elementos que no son percibidos como componentes distinguibles y analizables, pero que son "objetivos". De esta manera, el valor estético de "hermoso" de un cuadro de pintura, por ejemplo, formaría parte de la percep- 
ción como un elemento añadido al análisis de componentes (trazos, colores, valor estético) y la misma percepción no sería reducible a los componentes estrictamente perceptuales, sino que existiría un "plus" de significación que incluiría los valores. Y estos valores deberían formar parte de la realidad tal y como la percibimos. En la medida en que esa percepción tenga que ver con la realidad "objetiva", el valor o valores asignados a la percepción formarían parte de la realidad. Desde aquí se pasaría a postular que la percepción "objetiva" de esos valores podría justificar la existencia de valores y sistemas de valores, unos mejores que otros $y$, su generalización en el plano de análisis de sociedades podría desembocar en unas sociedades "mejores" y más cercanas a la perfección que otras, lo que podría justificar la "sustitución" de un sistema social por otro. El caso es que se puede ser empirista, axiológicamente comprometido y defensor del pluralismo ético y social democrático con la aceptación de valores dentro de las ciencias sociales. Veamos.

De entrada hay que decir que nada hay en la percepción que lleve necesariamente a posicionamientos ideológicos democráticos o no, en el ordenamiento social. El hecho hipotético de poder incluir los "valores" dentro de las percepciones implica que la percepción, o determinadas percepciones, son algo más que procesos cognitivos responsables de la detección cognitiva de la realidad, y que, de la misma manera que puedan percibirse valores "buenos", pueden ser percibidos los "malos". Lo que se haga después con estas percepciones no depende exclusivamente de la percepción, sino de las interacciones entre procesos y de la aplicación de valores a la conducta, lo que exige procesos inferenciales complejos y ese camino no es detallado ni por los gestaltistas, ni por los mecanicistas y en ausencia del conocimiento de ese proceso, pueden derivarse posicionamientos diversos y hasta contradictorios.

También parece que es verdad que existen "acciones" cuyo valor es claramente negativo (como el canibalismo, por ejemplo, o el asesinato) y otros que son claramente positivos como el altruismo o la ayuda a los demás en caso de necesidad. $Y$ en ambos casos pueden realizarse al margen de que sean percibidos los valores de manera independiente de los hechos o inmersos en ellos.

El caso es que las acciones y procesos psicológicos llevan consigo juicios de valor, conscientes o automáticos y posiblemente una de las maneras que existen para separar los componentes de esas acciones y procesos consiste en la toma de conciencia de esos componentes, lo que se puede obtener tras análisis más o menos laboriosos. De ahí a la "justificación objetiva" de acciones colectivas (como la guerra o campañas de exterminio de humanos) hay un largo trecho que no ha encontrado explicación justa y adecuada de los procesos componentes y de sus transformaciones, al igual que sucede entre el metabolismo bioquímico de la transmisión neuronal y los estados afectivos, o los registros actuales de la neurociencia y la dinámica de los procesos afectivos y cognitivos complejos. O dicho con otras palabras: la acción psicológica lleva implícitos valores, conscientes o no y el científico debería ser consciente de aquéllos que se encuentran presentes en su actividad como científico. 
Así, por ejemplo, sucede con la inteligencia, cuya medida y aplicación social representa, todavía en nuestros días, la mayor aportación práctica de la psicología a la sociedad. La promoción de la inteligencia fomenta valores de eficacia y eficiencia, que pueden ser utilizados para la promoción de una sociedad más justa o, como ha sucedido con demasiado frecuencia en los últimos 30 años, para el provecho individual $y$, en bastantes ocasiones, en contra de los intereses del cuerpo social. A la vez ha promovido un desarrollo de los medios de comunicación social, comunicación personal y la difusión del conocimiento mediante la informática. La corrupción tan frecuente en los últimos años en el mundo de los políticos no hubiera sido posible sin un crecimiento en la eficacia de sus gestiones y al margen, cuando no en contra, del sistema legal existente. Sin que represente una solución inmediata y/o definitiva, parece que a la promoción de la eficacia debería acompañarse la de la colaboración y conductas éticas y honestas. Y ello sería una salida para actuaciones sociales y educativas en la medida en que se promoviera no solamente la "sociedad del conocimiento" sino, que ésta estuviese acompañada de una "sociedad ética", lo que implicaría el estudio y cultivo de la sabiduría, como componente esencial de la eficacia y la eficiencia personal y social. Bien entendido, por lo demás, que en esta propuesta ni se propone un igualitarismo humano intra-específico (en el que se asume que todos los humanos somos psicológicamente iguales), ni la ética y la convivencia exige la creación de una sensibilidad y referencia de grupo en todos los casos (una de las versiones de la propuesta de aplicación de sabiduría exige la toma en consideración de los demás y los intereses intra- e interpersonales para que se dé la sabiduría), ni la sabiduría excluye la individualidad humana (pero sí el individualismo, entre la propuesta colectivista y la promoción del individualismo existe la posición del "vive y deja vivir" en la que una persona puede promover su individualidad e intimidad personal sin extorsionar ni explotar a los demás). En el pluralismo ético caben tanto las opciones colectivistas como las individuales, con tal de no perjudicar a los que nos rodean y con los que convivimos. Y ante esta cuestión, la sabiduría, asimismo posee un importante papel que desempeñar. $\mathrm{O}$, dicho con otras palabras, la sabiduría se encontraría ubicada en la gestación, elaboración y emisión de juicios y acciones en los que se toman en cuenta juicios de valor (y de valores positivos) de esos juicios y acciones $y$, por ello, deberían formar parte tanto del sistema educativo como sanitario y del trabajo en organizaciones.

\section{b. Tiempo físico, histórico y psicológico: continuidad y discontinuidad, colectivismo e individualismo.}

Los seres humanos vivimos en un espacio y durante un tiempo limitado. Podemos elegir el espacio en el que vivimos, con márgenes muy amplios, o en el que se vaya a vivir, pero no podemos (hasta hoy) cambiar el tiempo en el que vivimos (solamente muchas de las cosas que en ese intervalo temporal suceden). El tiempo físico transcurre, usualmente, de manera continua, monótona, con repeticiones en diversos aspectos, como la climatología, pe- 
ríodos anuales y períodos más largos, y hasta cansina (en grandes períodos temporales el tiempo transcurre de manera uniforme, aunque en alguna ocasión, se producen cambios radicales en el espacio vital humano, que, hasta el momento, no puede controlar, como los terremotos o las erupciones volcánicas) aunque la percepción que tenemos, usualmente, se refiere a cambios discontinuos de manera que el "tiempo físico" y el "tiempo psicológico" no suelen ir a la par; aquél pasa de manera uniforme mientras que éste se acelera o desacelera en función de los contenidos de experiencia que lo llenan y dan sentido. Cuando se pasa del análisis del caso individual y referido a cortos períodos temporales, al análisis del funcionamiento socio grupal ampliando el período temporal, las disonancias entre continuidad y discontinuidad, relevancia e irrelevancia se mantienen e incluso se magnifican, del mismo modo que aparecen discontinuidades e influencias de distinta frecuencia, duración e intensidad cuando se trata de apresar las relaciones entre el tiempo histórico con sus características y el tiempo psicológico-individual y las suyas.

Las reflexiones que se acaban de ofrecer desean ser una llamada de atención acerca de las explicaciones "historicistas" en las que se supone que las épocas y tiempos históricos dentro de contextos espaciales determinan maneras uniformes de pensar, sentir y actuar para todos los ciudadanos; pero también acerca de las interpretaciones "personalistas" en las que un ser humano crea épocas históricas y determina, en gran medida, las maneras de pensar, sentir y actuar de todos los demás (una parte considerable de la "historia oficial" defiende esta versión individualista y, en especial, en los movimientos culturales y artísticos, ignorando que los cambios deben ser aceptados y hasta propulsados por el grupo de referencia). Tal y como se observa en el mundo contemporáneo, estos individuos tienen, detrás, aparatos de presentación, difusión y propaganda asentados en medios de comunicación social (hoy las "redes sociales") que pueden crear "modas" de sube y baja, modas que se devoran sucesivamente; y por otro lado, el número y complejidad de grupos sociales dificulta considerablemente la aparición de modos de pensar, sentir y actuar comunes que se consoliden y creen seguidores creyentes y fieles durante largos períodos temporales.

El curso histórico se da al margen de las experiencias de los individuos y es una cuestión de conveniencia y hasta de didáctica, separar este curso continuo en bloques con un principio y un final. Troceamos el curso histórico para generar modelos raciomórficos acerca de sucesos a los que atribuimos importancia histórica y que sirven como puntos de referencia de los que hacemos depender los sucesos e ideas que son tomados en cuenta para elaborar modelos de funcionamiento personal y social. No representa una solución satisfactoria acerca de la comprensión de la historia que ha sucedido, pero lo hecho hasta el momento representa un avance al promover modelos más o menos justificados "racionalmente" acerca de las realidades vividas por la comunidad que ayudan a "entender", aunque de manera muy parcial, la evolución humana (pese a los sesgos hacia la primacía de las comunidades humanas occidentales). 
Sin que exista ninguna razón especial, muchos puntos de ruptura del curso histórico se hacen coincidir más o menos con el comienzo y/o fin de centuria y milenio. $Y$ en esta época, estamos más o menos en esa "área de influencia", que, además, tiende a colorearse con tintes pesimistas de crítica social, existencia de crisis profundas que implicarían un cambio de época e incluso de cultura, junto con la aparición de novedades y "progresos", que sirven como un necesario equilibrio que permite seguir viviendo. El ciudadano de a pie tiende a percibir estos períodos sin solución de continuidad a menos que coincidan con hechos trágicos (guerras o desastres naturales, pero también crisis económicas como la que nos está tocando vivir) y tan solo después de haber pasado se intentan dimensionar y caracterizar esos períodos. Ahora parece que nos encontramos en uno de estos períodos de crisis.

$Y$ en esta concepción parcial e imperfecta de la historia, al menos de parte de oriente y de occidente, sin que conozcamos las causas, hace unos 3.000 años surgen en Asia movimientos en los que se predica una actitud y manera de pensar diferente ante el mundo y la vida social: Buda y Confucio defienden un respeto hacia el mundo físico, una actitud de contemplación ante la vida propia y ajena y un respeto hacia uno/a mismo/a y los demás. Y todo ello orientado hacia una concepción del mundo que lleva y proviene de unas maneras concretas de actuar. Pese a las diferencias entre estas dos orientaciones (que no son las únicas, habría que incluir, al menos, Mesopotamia y la India) estas visiones de la realidad representan las primeras formulaciones más o menos siste- máticas de lo que denominamos en la actualidad "sabiduría" y que frente a una actitud belicosa y violenta de intervención ante el mundo físico y social, proclaman otra de comprensión y respeto. Desde Asia, a través de Grecia, se incorpora, tras unas significativas variaciones, al pensamiento religioso y filosófico occidental. Y con el proceso de industrialización y secularización del conocimiento, tiende a ser ignorado por las orientaciones socialmente dominantes desde hace casi dos siglos.

\section{c. Dos fenómenos relacionados con la crisis actual: el "fin de la historia" y los anti- sistema.}

En la sociedad occidental, sin propósito alguno de agotar el tema, habría que señalar la aparición desde finales del siglo $X X$, de algunos intentos realizados por entender la situación actual por un lado, a la vez que ofrecen o pergeñan opciones alternativas más o menos elaboradas ante el sistema social actual (básicamente occidental y/o neoliberal y capitalista). Dos de estos movimientos son la propuesta del "fin de la historia" (hacia el final del siglo $\mathrm{XX}$ ) y los intentos por generar sistemas sociales alternativos, incluyendo el rechazo del actual (los denominados movimientos anti-sistema).

La propuesta del "fin de la historia" sugerida por Fucuyama a finales del siglo XX, asume que la sociedad (occidental, claro, y más específicamente la estadounidense) habría llegado a su máximo exponente de bienestar y las instituciones serían y funcionarían de modo prácticamente perfecto, por lo que la historia, como cambio significativo de futuro, acabaría: instituciones y personas seguirían viviendo pero 
con cambios muy superficiales y accidentales, y se mantendría, esencialmente, el estado actual. Esta propuesta demostró en menos de 24 meses su fracaso total. Como elementos sustratuales y falaces de este posicionamiento se encuentra la idea de que (a) la historia existente se restringe a los países del primer mundo, (b) se asume que esa historia es la única posible y los estadios de evolución de esa historia son generales y los que siguen todas las sociedades humanas; (c) los principales elementos de evolución histórica se encuentran comprometidos con bienes materiales, una gran posesión de los cuales va aparejada con un mayor grado de felicidad; (d) la evolución social se daría por igual en todos los dominios (económico, político, sanitario, educacional, industrial-tecnológico), lo que no es el caso; y sería aceptado y promovido por todos los sectores sociales por igual y (e) el progreso en eficacia social e industrial se iguala al de solidaridad y colaboración entre humanos, lo que no se parece mucho a lo que sucede a nuestro alrededor.

La "historia" es posible que haya acabado, al menos tal y como se entendía hace unos años de historia universal como historia de occidente, de los avatares de poder y guerras de los denominados "países occidentales" porque se ha ampliado notablemente el conocimiento $y$, con él, el papel que ha desempeñado y desempeñan otros pueblos y latitudes en el curso histórico total (si es que puede detectarse esa evolución histórica total, lo que, hasta el momento, no se ha logrado). Y, además, como se verá más abajo, es posible pensar que no exista un "curso histórico universal" para todos los seres humanos, con sus períodos comunes $y$, en todo caso, con fases de "evolución comunes", sino historias parciales que deben ser entendidas en función de los contextos en donde han ocurrido y están ocurriendo 5 .

Por otro lado, desde el último cuarto del siglo XX aparecen, como cometas dentro del universo conceptual, intentos de corte muy distinto y que poseen en común la crítica al sistema actual occidental ${ }^{6}$ en países económicamente desarrollados y con regímenes democráticos.

El post-modernismo se caracteriza por su intento crítico por acabar con el sistema de producción y relaciones humanas propias de la sociedad productiva y de consumo. En lo que se refiere a ciencia y epistemología científica se identifica con una posición constructivista en la que el consenso y la construcción personal y social son elementos claves. En cierto modo, forma parte de los distintos movimientos antisistema que están proliferando en los últimos años, aunque sus propuestas no defienden la violencia física sino cambio en formas y expresiones ideológicas y de pensamiento; y tampoco puede defenderse con nitidez que los autores se identifiquen a sí mismos como grupo. El modelo social sometido a crítica es el productivo en donde la economía, la rentabilidad y la industria desempeñan papeles principales. Unos ejemplos de autores e ideas pueden iluminar este punto.

5 Con la colonización occidental de África, Asia y algunas zonas de Australia, ha habido pueblos y culturas que han pasado desde un neolítico a la industrialización de manera rápida y sin que se pueda distinguir con claridad las "fases históricas" europeas. Y, como reflexión, repárese que en el oeste de Estados Unidos sucedió otro tanto.

6 Existen opciones muy distintas que van desde el activismo de la guerrilla urbana y grupos terroristas con ideología revolucionaria, hasta propuestas en las que se detectan insuficiencias claras del sistema actual, como sucede con el postmodernismo. Estos intentos post-modernos han aparecido tan solo en los países del primer mundo. 
Lyotard $(1979,1986)$ defiende la diversidad frente a la uniformidad que se encuentra presente en las grandes explicaciones de la historia (no existiría una historia universal común de la especie humana, sino historias y narraciones parciales, diversas entre sí de acuerdo con las culturas distintas existentes). En la sociedad contemporánea se ha perdido el valor del conocer por conocer y se ha sustituido por la eficacia en la comunicación y las aplicaciones a que dé lugar ese conocimiento, se busca la utilidad inmediata frente a la inversión a medio y largo plazo, el qué son las cosas y el sentido que poseen se ha sustituido por el cómo se hace y para qué sirve; la propuesta consiste en la gestación de narraciones (historias) parciales y contextuadas, la defensa del pluralismo porque las diferencias entre humanos, de hecho, son incomparables entre sí y el individuo debe tener un valor prioritario frente al grupo.

Frente a los procesos y sistemas de "modernización", como las grandes empresas, las cadenas de montaje, la industrialización y la excesiva burocratización con el control perseguido y muchas veces logrado del Estado sobre los ciudadanos, Inglehart (1977, 1990, 1991) defiende el cultivo de la amistad, la libertad del individuo, bienestar y crecimiento de la esperanza de vida con la máxima disminución de la burocratización (protocolización). Bauman $(1993,1995)$ por su parte, insiste en los aspectos éticos que diferencian modernismo y postmodernismo. Frente a la existencia de un solo código ético, la homogeneidad del funcionamiento institucional (e individual) y la claridad y concreción de prescripciones, en el postmodernismo se reconoce la existencia de frecuentes situaciones ambiguas, pluralismo ético y tolerancia. Los mecanismos de control excesivo social, que caracterizan al estado moderno han llevado al ciudadano a una desconfianza y pérdida de credibilidad del sistema.

Junto a la idea del fin de la historia y del postmodernismo aparece, como elemento sustratual que existe solamente un tipo de curso histórico y que el logro de la felicidad se alcanza a través de la posesión de los bienes materiales (cuanto más rico, más feliz). El caso es que la narración del curso histórico, hasta ahora, más que representar una función lineal en el sentido de que se logra un mayor "humanismo" a medida que se avanza en el tiempo histórico y se van proporcionando mayores bienes materiales, muestra vaivenes de pequeños adelantos y retrasos, de períodos de paz y de guerra intermitentes en los que, a mayor número de habitantes, mayor número de muertos en los conflictos bélicos. Y, por otro lado, al menos en el período en el que existen datos sobre estimación subjetiva de felicidad de los ciudadanos en los países occidentales avanzados, no es verdad que a mayor bienestar material mayores cotas de felicidad percibidas y sentidas ${ }^{7}$. Y este tipo de resultados deja la puerta abierta hacia la búsqueda de otras maneras de entender y promover la felicidad y el bienestar humano de los ciudadanos.

7 Por ejemplo, aquellos a quienes les toca un premio cuantioso en la lotería, no se convierten, de inmediato, en personas felices. Después del entusiasmo del momento que se alarga unas semanas, se vuelve al estado o nivel de felicidad anterior, si no disminuye. $Y$ sucesos parecidos se dan en las personas cuando alcanzan un objetivo importante en la vida, como puede ser recibir una herencia copiosa o lograr el amor de la persona amada. La "felicidad" parece agotarse y se vuelve a una situación anterior a estos hechos, o un poco peor que con anterioridad. 
La sabiduría resulta de considerable interés en este movimiento en la medida en que se defiende la existencia de un tipo de epistemología múltiple en la que la ciencia representa uno de los tipos, pero, asimismo debe incluirse una manera de conocer propia de los asuntos de convivencia y ética humana, la defensa de la diversidad-individualidad frente al colectivismo uniformista de "lo general" y la posible existencia de más de un tipo de sabiduría que tendría papeles distintos en función de los contextos y dominios de vida, así como el subrayado de la importancia de modelos funcionales distintos al del incremento en eficacia y productividad industrial.

Si bien los ejemplos comentados detectan problemas de funcionamiento del sistema, no ofrecen una alternativa viable que permita su puesta en práctica inmediata. La primera (el fin de la historia) es una utopía que ha demostrado su inutilidad y la segunda (el postmodernismo) detecta problemas aunque no ofrece soluciones viables y además, ignora el mundo del trabajo y eficacia, que no puede encajar en ninguno de los esquemas y tratamientos propuestos. El postmodernismo sugiere, en buena medida, la necesidad de poner en práctica nuevos esquemas éticos y de conducta de interacción personal fuera del horario laboral, y considera mal en sí mismo el mundo de la productividad social y material, lo que dejaría abierta la puerta a la posibilidad de generar nuevas prácticas educativas que llevaran a una convivencia más apacible y humana; desde aquí se podría introducir la sabiduría (o sabidurías) como una de las guías para gestar esas nuevas prácticas educativas y con ello, ade- más, establecer nuevos objetivos. Claro que no se trata de sustituir la eficacia por la sabiduría, sino añadir sabiduría a la eficacia productiva, para crear una sociedad más humana.

Y, por supuesto, que los movimientos antisistema violentos que pretenden romper y destrozar el sistema actual no ofrecen un modo viable de vida que sea más satisfactorio. Ante la pregunta ¿y después de la revolución qué? Las respuestas son ingenuas y alejadas de la realidad y diversidad humanas, cuando no se proponen caminos hacia regímenes autoritarios.

\section{d. Alternativas intra-sistema: religiones} laicas, organizaciones no gubernamentales y "realidad virtual".

También existen instituciones y/o organizaciones que forman parte del sistema como "pobladores" y hasta fautores. Unas son una suerte de "religiones laicas", que exigen fe en su existencia y valor, se supone que son imprescindibles para el funcionamiento social, como los partidos políticos, la ciencia y el mercado. Otras se han incardinado hasta tal punto en la vida del ciudadano del primer mundo que sin ello resulta muy difícil pensar en el modo de vivir actual: la "realidad virtual".

(i). Las religiones laicas.- Un fenómeno casi ausente en cuanto a su tratamiento psicológico es el de la espiritualidad y religiosidad. La investigación se ha centrado en el estudio de las creencias y se ha ignorado hasta el punto que se ha ignorado que casi la mitad de la población mundial confiesa tener una u otra fe religiosa. En las sociedades occidentales, sometidas a un proceso de secularización desde 
hace algunos siglos, ha ido ganando terreno el espíritu positivista. En la medida en que el ser humano durante varios miles de años ha estado viviendo con creencias e incluso vivencias religiosas, parece que el lugar que ocupaba la religión en esas sociedades se ha visto sustituido por otras entidades que son depositarias de sistemas de creencias con veracidad asentada en la fe, a las que se les da un plus significativo de valor supremo, o casi supremo, y en donde los líderes han sustituido a los santones y anacoretas, a los que se envuelve en un halo de misterio e incluso de misticismo por conocedores "con prestigio" en los respectivos campos de estudio (especialistas, magos de las finanzas o científicos especialistas).

Tres ejemplos de todo ello lo representan los partidos políticos, la ciencia y el mercado.

En un principio, los partidos políticos surgen como organizaciones que representan la pluralidad de ideas y acciones presentes en el mundo social para su organización y gestión. Lo que al principio servía como un criterio de selección de líderes sociales por mérito, en sustitución de la sangre (o la familia), se ha convertido en un tipo de organización compleja, cuya actividad básica se orienta al logro y detentación del poder, y que se agrupan alrededor de unos pocos líderes a los que se inviste, por el mero hecho de ser elegidos, de un conjunto de cualidades positivas y conocimientos copiosos, especializados para los puestos que desempeñan y sin refrendo empírico de esos conocimientos. Se crean verdaderas imágenes sin fundamento real y que, usualmente van permeabilizando al propio líder que acaba creyéndose la imagen que del líder, han crea- do sus "colaboradores". Los especialistas en el "manejo de la opinión" (los líderes democráticos) se convierten en especialistas de todo aquello que puebla el mundo social. Aunque la situación puede mejorar con la incorporación de "asesores", estos asesores no tienen responsabilidad de decisión, que, al final tiende a ser mediada por la ideología y objetivos perseguidos por el partido político, sus partidarios "especialistas" y parte de su programa electoral (que vendría a ser el libro sagrado de cabecera que guía sus actos). Estos se convierten en los traductores de las necesidades y objetivos que tienen los ciudadanos y sus discursos se encuentran montados no sobre resultados empíricos y opciones alternativas de acción, sino desde la estructura ideológica que defienden (que "asumen" es la de la "inmensa mayoría de los ciudadanos"). El camino termina con una organización en la que los miembros directivos (los líderes) se encuentran muy alejados de los intereses y problemas reales de los ciudadanos (así, un discapacitado, lo mismo que un parado y un enfermo es uno entre todos los que se encuentran en esa situación, se convierten en estadística, perdiendo su humanidad). Cumplen, muchas veces, con opciones de consolación teórica, pero no tienden a resolver los problemas que, realmente, aquejan a los ciudadanos sino aquellos otros relacionados con el mantenimiento o incremento de poder). $Y$ tienden a ser percibidos como santones todopoderosos y en lucha constante entre el bien (lo que ellos defienden) y el mal (lo que defienden los demás). Los gobiernos que se forman con ellos no están pensados para resolver los problemas sino para llegar y mantenerse en el poder, así 
como crear y gestionar presupuestos con escasa información acerca de los efectos que todo ello produce en el cuerpo social. Resulta claro a la luz de los resultados, que ni los líderes ni los cuadros directivos son elegidos en función de su talante ético ni de la prudencia, que parece necesaria para la toma de decisiones políticas. Y no deja de resultar curioso que, a pesar de que resulta casi una constante histórica entre los teóricos de la formación de líderes políticos esa prudencia, no resulta ni un criterio de selección actual, ni de promoción y práctica en el mundo de los partidos políticos. Y la prudencia es un factor básico en la sabiduría.

El papel de la ciencia desde el siglo XIX convierte al científico en una persona competente en un campo de estudio (muchas veces delimitado por los propios científicos) y cuyo trabajo se encuentra regido por normas metodológicas rígidas (una especie de ascética mental), que debe separarse del mundo para poder entenderlo $y$, al igual que en las religiones, existen "autoridades", clásicas y contemporáneas, reciben un cierto reconocimiento social y en su nombre (que no en sus resultados) se llegan a justificar muchas decisiones políticas. Social y políticamente, se considera que lo serio y verdadero es "lo científico" y a ello se acude en situaciones de falta de salud, en cuestiones que a los líderes sociales les interesa nombrar a la ciencia (que no, que sea entendida y aplicada en sus justos términos) y en sus aplicaciones (la tecnología) es explotada por líderes políticos y económicos. En lugar de ser presentada como un proceso activo y cauteloso en cuanto a la generalización de sus resultados, se presenta (en la sociedad e incluso en los libros de texto) como algo dogmático y no probabilístico y dependiendo de que se cumplan ciertas condiciones. Las autoridades académicas reconocidas actúan, en demasiadas ocasiones, como tribunales inquisitoriales promoviendo unas ideas y soslayando otras sin razones suficientes en muchos casos, pero que sirven para conservar el status quo de la situación en la que detentan el poder. El resto de científicos, y más en los últimos años, se dedican a "contrastar" las hipótesis derivadas de los modelos y teorías generadas por unos pocos de ellos.

Por lo que se refiere a la percepción que poseen los ciudadanos de la ciencia, llegan a hacerla depositaria de la posibilidad de eliminar muchos de los sufrimientos provocados por las enfermedades, en especial del dolor, así como el incremento en la esperanza de vida (que sustituye a la "salvación"). La fe en la medicina (en el último siglo y medio) se encuentra mediada por la fe en la bioquímica a la que se considera que "magnifica" al ser humano, incrementando en unos casos sus potencialidades $y$, en otros, pudiendo proporcionarle una vida sin miedos ni ansiedad. Esta fe no se ajusta a la realidad, ni representa una solución, sino parches que poseen efectos secundarios nocivos, no siempre previstos ni siempre controlables. Una imagen más cercana a la realidad es que no existe la ciencia sino "las" ciencias, que representan conocimientos parciales de la realidad, con limitaciones metodológicas no resueltas para poder estudiar todos los temas relevantes para el ser humano y asentados sobre la contrastación empírica (que no lógica) de las hipótesis concretas, que se generalizan, muchas veces, de modo infundado, acerca de todas las cues- 
tiones imaginables. En las últimas décadas, se predica la prudencia en la aplicación de conocimientos y la cumplimentación de una escala de aproximación desde los análisis de laboratorio hasta el mundo de la aplicación a humanos, aunque, desgraciadamente no siempre se cumplen estos requisitos. Y no sería accidental ni gratuito insistir más en la manera de pensar y hacer ciencia de los creadores, en lugar de apelar a los manuales de metodología de diseño experimental como libro de consulta obligado.

Desde la perspectiva de la sabiduría, la ciencia debería presentarse y cultivarse como una actividad compleja, difícil y cambiante (los propios creadores de ciencia van evolucionando a medida que se introducen en los temas que estudian y modifican desde sus plataformas conceptuales hasta el límite que poseen las interpretaciones correctas de sus resultados y formulaciones). De nuevo, aparece la prudencia y aquí ya claramente la tolerancia de la incertidumbre-ambigüedad como un elemento clave, junto al pensamiento original y de síntesis de lo realizado por el científico mismo y otros científicos.

Un tercer ejemplo es el mercado. En la actualidad parece que las cosas y decisiones valen lo que pagan los mercados por ellas, como si ello fuera un credo de fe obligatoria. Y las decisiones políticas y sociales tienden a orientarse y justificarse en función de las respuestas y condiciones funcionales del mercado que pueden llevar a hipotecar a países enteros (lo que está sucediendo en estos años) y, desde luego, "dictan" $y$ "justifican" las decisiones sobre política social.

Frente a este tipo único de poder, una tendencia que se puede detectar en las socieda- des modernas es la pluralidad de decisiones y batallas políticas entre la descentralización y división de poderes y la tendencia a la concentración de poder. Ejemplos de tales conflictos son el intento de distintos gobiernos por controlarlo todo y los esfuerzos de los ciudadanos por mantener una cierta autonomía, la división de poderes (legislativo, ejecutivo, judicial, medios de comunicación) frente a los intentos por concentrarlos alrededor de quienes desempeñan el gobierno, separación entre iglesia y estado, o el poder gubernamental frente al poder de comunidades autónomas y/o estados federados y el poder económico frente a todo el resto de poderes, son ejemplos de ello.

El uso de las capacidades de análisis racional y matemático para incrementar el beneficio personal ha ido creciendo y con la globalización, el "mercado" actual, funciona 24 horas al día alrededor del mundo, con unas fuerzas de presión cuyo lema es maximizar los beneficios, el mercado es avaricioso y egoísta y se encuentra influenciado por personas que representan fuerzas de presión cuyo único objetivo es el beneficio personal o de sus corporaciones. Las leyes que los rigen parecen encriptadas ${ }^{8} y$ además, pueden ir modificándose en función de la presión de esas fuerzas que se encuentran ocultas y no pueden contrastarse con la metodología científica al uso que no sea el propio beneficio (lo que significa el maleficio

8 En alguna ocasión se ha ilustrado como ley fundamental que posee la sociedad civil para limitar el mercado, el manejo del egoísmo y como metáfora, la situación en la que se presenta una tarta que les guste mucho a dos niños de alrededor de 9 años que desean comérsela. Se expone la situación de manera que debe haber para los dos. Se decide a suerte que uno de ellos parta la tarta $y$, posteriormente... se le pide al otro niño que elija la parte que desee. Esta lógica aminora algunos efectos indeseables, pero no resuelve el problema de la maximización de beneficios. 
para otros). Sucede, además, que en la sociedad contemporánea, la obtención de ganancias económicas genera una suerte de adicción de manera que la persona que se dedica a ello, cada vez, dedica más tiempo y esfuerzos a obtener beneficios, en detrimento del resto de aspectos que definen la actividad humana.

Oscuridad, "verdades reveladas" (o información privilegiada), personas dedicadas día y noche al logro de sus objetivos de maximización de beneficios, son elementos que junto a un incremento de capital (con realidad virtual todo él) forman el credo y el principal mandamiento de este modo de proceder, en el que el resto de elementos que forman la cultura humana se van progresivamente devaluando y desapareciendo. La desmesura del poder de los mercados ha fomentado la avaricia y la pobreza y explotación de grandes sectores de la sociedad y no ha solucionado los problemas creados en la convivencia humana, antes bien, los ha incrementado.

La sabiduría se encontraría en una posición antitética a la de la sacralización del mercado y debería representar un freno a las decisiones económicas de cumplir con las leyes del mercado (que representan, en el fondo, el beneficio de unos pocos ciudadanos a costa del sacrificio de otros muchos).

(ii). Las organizaciones no gubernamentales.El establecimiento de regímenes democráticos en los países occidentales ha propiciado el re-análisis del mundo social y la detección de problemas en ellos que no son cubiertos por las políticas de los distintos países. Los intentos se han plasmado con la aparición de organizaciones surgidas de la sociedad civil, e indepen- dientes, teóricamente, de la acción gubernamental. No se trata de elementos totalmente nuevos, en la medida en que, como aspectos secundarios de la religión, aparecieron desde hace bastantes siglos, movimientos religiosos que se encargaban de llenar como podían esos huecos especialmente en momentos de crisis social y sanitaria (las epidemias y crisis sociales o fenómenos naturales como terremotos ${ }^{9}$ ); en la sociedad moderna, esos movimientos se identifican como organizaciones laicas que funcionan económicamente, originalmente, gracias a la iniciativa privada, pero que como práctica habitual en España, al menos, reciben subvenciones del Estado (en una suerte de política social secundaria y voluntarista). Se trata de organizaciones sin beneficio propio que actúan sobre uno u otro aspecto del sistema social (en los últimos años, prioritariamente, para proporcionar alimento y cobijo a las personas socialmente necesitadas). Estas organizaciones comprenderían desde fundaciones para el fomento del conocimiento y la cultura hasta grupos con una organización mínima que se dedican a llenar los huecos de servicios sociales que no son tomados en consideración ni forman parte de los presupuestos generales del Estado y demás instituciones sociales gubernamentales.

Estas organizaciones no resuelven los problemas pero si han representado y representan un alivio de urgencia para muchos ciudadanos

\footnotetext{
9 En buena cuenta, las órdenes religiosas de hombres y mujeres, heréticas o no, desempeñaban estas funciones. Con el proceso de secularización (o de-sacralización) social acelerado desde el siglo XVIII, estas funciones se están ocupando por las asociaciones no gubernamentales, tanto por lo que se refiere a cuestiones de salud (por ejemplo, los "médicos sin fronteras") como sociales (caritas, asociaciones y fundaciones de ayuda a drogodependencias, etc.).
} 
que se encuentran en el nivel de la pobreza o cercanos a ella. Pero no representan una solución a los problemas que alivian, sino tan solo una ayuda, importante pero no prioritaria para los distintos gobiernos, ni forman parte de las fuerzas de presión extra-gubernamentales que conforman los sistemas democráticos occidentales, en la medida en que dependen en gran medida para su subsistencia, de las subvenciones gubernamentales.

De inicio habría que señalar que estas organizaciones representan la promoción y plasmación de solidaridad entre humanos, facilitación de convivencia y ayuda, que son elementos presentes, asimismo, en la sabiduría.

(iii).La realidad "virtual".- El gran desarrollo de la informática y, en general de los medios de comunicación ha producido una manera hasta de percibir la realidad que no es tangible sino artificial, generada por instrumentación humana. Hay que señalar que la diferencia entre estas dos realidades no es fácil de determinar a nivel teórico (excepto en el caso del curso temporal, que es, hasta el momento, unidimensional y dirigido hacia adelante en el caso de la "realidad natural"10). Existen tres tipos de realidad virtual: la que recoge dimensiones y pautas normales (las usuales), la denominada"realidad aumentada" y la "realidad disminuida". En estas dos últimas se amplifica la realidad tal y como es percibida (existente ya en cinematografía desde hace muchas décadas, mediante

10 La "realidad", incluso física, no se capta "directamente" sino a través de las mediaciones y limitaciones de los sentidos o analizadores sensoriales, que se codifican en el cerebro, modificando la señal que procede del exterior y, por ello, es "mediada". A esta mediación añade, la realidad virtual, que es creada por el ser humano y presentada como elemento "connatural". En ambos casos existe mediación y no captación "directa". recursos ópticos y sonoros) o se disminuyen las dimensiones, frecuencias o intensidades. $Y$, además, se pueden "crear" realidades virtuales y no solo reproducir la realidad usualmente percibida, modificando dimensiones, en nuestros días, con el uso de ordenadores y programaciones adecuadas.

Las aplicaciones de esta realidad virtual en nuestros días se extienden a muchos campos, desde casi todas las ciencias (medicina diagnóstica y terapéutica, física, astronomía, biología, psicología, sociología, economía) a juegos informáticos y ocio. $Y$ es posible modificar representaciones "fieles" de la realidad natural mediante la aplicación de técnicas informáticas hasta el punto que el mundo de la falsificación y suplantación está alcanzando niveles en donde resulta muy difícil la diferenciación entre lo natural y lo virtual. Y el crecimiento de las realidades virtuales están generando, junto a recursos de ayuda terapéutica, tipos de relaciones personales virtuales en donde la presencia física no es requerida y ya existen muchas personas que prefieren esas relaciones virtuales en lugar de enfrentarse a la realidad natural, lo que genera aislamiento y ritualización de relaciones. El ser humano, en los países del primer mundo, se encuentra en un proceso laborioso, activo y largo de adaptación psicológica a estos cambios, cuyas repercusiones para el funcionamiento humano todavía son poco conocidas. Asimismo en los diversos programas y distracciones sería muy conveniente la introducción de elementos de sabiduría tales como la prudencia o la tolerancia de la ambigüedad, que permiten el fortalecimiento de la voluntad y de la persistencia en el logro de 
metas, que deben ser mediadas por elementos finalistas éticos de ayuda a uno/a mismo/a y los demás.

\section{e. Unas repercusiones no muy positivas acerca de la globalización}

Gracias al desarrollo de la informática, los medios de comunicación y el mercado, ha aparecido y desarrollado la posibilidad de tener mucha información que es instantánea, acerca de lo que está sucediendo en la casi totalidad del mundo a través de plataformas como internet. La información permite, además, el comercio de productos que pueden encontrarse en lugares muy lejanos a su producción en muy poco tiempo y se ha promovido la comunicación entre instituciones y personas que se encuentran espacialmente alejadas entre sí. Teóricamente, estas nuevas posibilidades deberían promover y potenciar las posibilidades de desarrollo humano, pero como sucede con la incorporación de novedades, aparecen peligros y desventajas.

De entrada, es verdad que existe posibilidad de intercomunicación entre humanos espacialmente alejados entre sí, pero se requiere un lenguaje común, y el propio lenguaje utilizado se va modificando con el uso de esos canales de comunicación (denominados, en los últimos años, "redes sociales"), haciéndose más rígido y, por ello, con menos posibilidades de expresión de sucesos o vivencias.

Uno de los últimos intentos propuestos para la solución de problemas es esta globalización, o generalización de posibilidades de mercado y de información para todos los habitantes del planeta, o, al menos, para la mayoría de países del primero y del segundo mundo. Los avances en informática han posibilitado que puedan tener conexiones las distintas fuentes de producción y de distribución de casi todo el mundo, lo que implica, entre otras cosas, (i) que el acceso a la información y/o al conocimiento ha crecido desmesuradamente; (ii) que un gran volumen de relaciones entre humanos, así como entre dominios sociales son virtuales y no presenciales; (iii) que la globalización genera, de hecho, problemas psicológicos en los habitantes de esas sociedades interconectadas, entre ellos, el proceso de aculturación y de identificación personal, junto con problemas para la intimidad de las personas; (iv) que existe un considerable peligro de desaparición o, al menos, disminución considerable del número e influencia de culturas que sean distintas a la propuesta por el movimiento de generalización $y$, con ello, de la diversidad humana; (v) confusión entre información y solución de problemas; (vi) aparición de una "personalidad virtual" en las redes de comunicación que puede ser o no la "real" y para lo que no existen, en la actualidad, recursos para saber la realidad de la ficción y, para no alargar más esta enumeración, (vii) el incremento en el poder económico de las personas puede ayudar a disminuir el volumen de problemas que existen en el actual sistema, pero no los resuelve, y (viii) de importancia mayor aunque menos visible en los primeros años es la imposición de un sistema de valores en los que la competencia, la competitividad, la búsqueda del éxito y un desequilibrio entre el valor asignado a la vida humana real y el teórico (realmente en Africa, 
por ejemplo, el valor de la vida humana es el de un proyectil, con masacres generalizadas de la población, a la vez que se defienden los "derechos humanos", que, por lo visto deben ser mantenidos, modificados y promovidos con armas y muertes); el análisis sistemático de estos sistemas de valores, el valor del relativismo moral y de los "valores democráticos", más teóricos que prácticos, se encuentra por hacer. Posiblemente, uno de los resultados más claros hasta el momento, como consecuencia de la última crisis económica es que el sistema, como tal, debe ser modificado en aspectos importantes.

Una de las consecuencias de esa globalización consiste en la aparición y generalización de bienes de consumo (incluidos los bienes culturales) similares en todo el mundo, desde música a vestidos, generación de ídolos y modelos e incluso maneras de contemplar y expresar la realidad. Este proceso de homogeneización lleva consigo, asimismo, la desaparición de diferencias culturales, lo que es rechazado por muchas personas que ven en ello la eliminación de sus culturas y tradiciones.

La aparición y diseminación de esa "cultura global" genera no solamente nuevos tipos de acercamiento entre ciudadanos sino, asimismo nuevas fronteras y objetos de discusión. De hecho, hasta el momento al menos, parece que predominan sistemas de pensamiento y de valores propios de la sociedad estadounidense, para bien y para mal (por ejemplo, individualismo, libre mercado y cierta forma de democracia, que poseen aristas de promoción de convivencia y tolerancia, pero asimismo, predominio de un idioma y manera de pensar influido por las posibilidades y limitaciones del desarrollo informático).

Como sucedió en la Edad Antigua con la muerte de Alejandro el Magno, el ciudadano de nuestros días se encuentra entre su propia cultura nacional y la de la generalización (ciudadano de un imperio en el que se diluyen las diferencias nacionales), lo que produce una bi-culturación que no siempre es coherente ni ayuda a integrar ambas series de fenómenos. En el plano individual, esta bi-culturación genera una identidad personal híbrida en donde se encuentran mezclados y a veces hasta revueltos, elementos de ambas culturas, lo que puede llevar a una integración positiva, pero asimismo, lleva consigo fenómenos de marginación (rechazo de ambas culturas, la nacional y la globalizada), toma de distancia de esas culturas, lo que deja un tanto inerme al individuo, conflicto de creencias entre ambas culturas e incluso echar a un lado ciertos patrones culturales tradicionales, como el reconocimiento de la autoridad de los padres.

Asimismo, la progresiva complejidad de los instrumentos a utilizar lleva consigo un retraso en la aparición de la toma de responsabilidades y obligaciones del adulto en las respectivas sociedades, lo que disminuye la fase de adulto productivo, necesario para el mantenimiento del sistema social. $Y$ este retraso se ve incrementado, en los últimos años, por la crisis económica que ha producido unas bolsas de jóvenes bien preparados pero sin puesto de trabajo posible en muchas sociedades, y el reconocimiento de la necesidad de reconversión del sistema educativo como preparación para la vida o dimensión de la vida misma. 


\section{f. Unos puntos de referencia respecto a} cambios relevantes en la sociedad contemporánea.

\section{i. La crisis de los partidos políticos.}

En Europa se ha ido diseminando la aparición y consolidación de sistemas democráticos como una de las metas a lograr en todos los países, asentado este fenómenos en el supuesto de que se trata del mejor (no perfecto) de los distintos sistemas de gobierno. Desde el último cuarto del siglo XX se han ido sucediendo crisis que han puesto en duda ese juicio de bondad tal y como el sistema se ha plasmado $y$, en la última y en España, la crisis ha venido envuelta en delincuencia de cuello blanco realizada por dirigentes sociales. $Y$ esto se encuentra acompañado por la creencia, medianamente fundada al menos, de que el sistema de partidos políticos ha traído consigo un gran control para los ciudadanos en general y una gran dosis de impunidad para la clase política, agrupada alrededor de los partidos políticos. Y no existe una clara alternativa y nueva, que valga como sustitución de lo que ahora existe.

Como cuestión de hecho, la democracia moderna surge con la Revolución Francesa y, desde entonces se ha intentado sustituir el mérito por la sangre (monarquía) a la hora de seleccionar los líderes que deben regir la sociedad. Para ello se propuso por el sociólogo alemán Max Weber, la creación de una "profesión" que permitiese seleccionar a los mejores líderes, lo que ha dado lugar no solamente a líderes con problemas para ser calificados como "los mejores" profesionalmente, sino, además, a sociópatas encargados de dirigir la sociedad (ciertas "formas" de democracia como título y la corrupción).
Esta "sociedad democrática", políticamente, se organiza y simplifica a partir de grupos organizados (partidos políticos). El curso histórico ha producido, (1) una diversidad de formas de democracia que identifica mejor a los partidos políticos por la ideología que defienden junto a las "opiniones" de los propios políticos acerca de todas las cuestiones, que un análisis racional y contrastable, justificado con datos relevantes y no sesgados de la realidad social; (2) tampoco se identifican ni son motivo central de las preocupaciones de los partidos políticos los problemas concretos de los ciudadanos, al menos, en nuestro país; (3) un tipo de organización (partidos políticos) que no es nada democrática y cuyo objetivo "teórico" es el logro de un mayor bienestar social para todos los ciudadanos y el práctico, operativo, el logro y mantenimiento del poder (que representa su profesión); (4) un tipo de "profesional" que lo es de la política y, posiblemente, en ese mundo, sí es competente, pero no fuera de la política parlamentaria misma; (5) en consecuencia, unos equipos de liderazgo (gobierno) mediocres cuando no ignorantes de muchos de los problemas que tienen que resolver (la polémica entre "políticos" y "tecnócratas" está muy vigente en nuestros días); (6) un progresivo incremento en burocratización y/o protocolización que ha generado el "mundo del parlamento" y "el mundo del gobierno" que tiene que ver con la estructura y dinámica política pero extraña al mundo social cotidiano, (7) y con todo ello, se ha producido un alejamiento entre el mundo del político y el del ciudadano que les vota, separación que, hoy por hoy, es insalvable; a todo ello se añadiría (8) la in- 
fluencia de grupos de presión económica que perturban, influyen, cuando no impiden las decisiones que deben adoptarse y las acciones a realizar y (9) los problemas detectados han generado una situación tan decepcionante que se ha llegado a definir la democracia como el manejo de la opinión, lo que tiene poco que ver con el "gobierno del pueblo y para el pueblo".

Todo ello exige un replanteamiento de las maneras de pensar y hacer de los regímenes democráticos existentes para evitar la aparición de conflictos sociales graves. Y. desgraciadamente, no parece conocerse alternativa operativa sobre ello y sí, por el contrario, una progresiva separación entre los políticos y el resto de ciudadanos, entre otras cosas porque ha nacido una nueva profesión: el "político parlamentario" que desempeña su actividad dentro del parlamento y para resolver los problemas que allí se plantean. Para el resto, se confunde la imposibilidad real de resolver los problemas que tienen planteados la mayoría de ciudadanos, con la escasa "voluntad política" para resolver esos problemas.

\section{ii. Medios de comunicación (informática y}

\section{comunicación)}

Uno de los progresos más notables en el conocimiento científico contemporáneo con impacto social lo representan los medios de comunicación (sistemas máquina-hombre y máquina-máquina).La televisión y la radio, el ordenador personal con sus posibilidades de obtención de información y comunicación con la mayor parte del mundo y la miniaturización de la instrumentación (el teléfono móvil) con las redes wifi está modificando incluso los va- lores y prácticas tanto de ayuda como de delincuencia en el mundo contemporáneo.

La televisión se ha convertido en un elemento tan frecuente que, en más de una ocasión, las personas invierten en la compra de una gran pantalla de televisión más que en las necesidades materiales primarias que necesitan. Los protagonistas de esa televisión (informadores y tertulianos) han pasado de ser "transmisores" de información en creadores de opinión sobre prácticamente todos los temas. $Y$ esas opiniones se van incardinando en la cultura popular y se convierten en temas de conversación (y con demasiada frecuencia, en los únicos temas de conversación). En alguna época de la vida, incluso, en los únicos temas de conversación desde edades muy tempranas (al principio, los dibujos animados, después programas de ficción y de opinión). Y la televisión promueve, como se ha dicho, un "homo insipiens" frente al "homo sapiens", un ser humano pasivo, receptor de información y hasta crédulo de las imágenes que se le ofrecen en televisión. La actividad racional más bien se disminuye en la medida en que se ofrecen informaciones empaquetadas y fácilmente entendibles.

El ordenador personal ha representado la posibilidad de vivir en una cultura virtual en la que el papel resulta un elemento poco necesario para la transmisión de conocimientos y para el establecimiento de comunicaciones. "Internet" representa una enorme cantidad de información (también de desinformación) sin que exista un control fácil de esa transmisión hasta el punto que se comienza a defender la idea de que lo que no está en internet no existe y que internet representa una fuente fiable de 
verdad en todos los casos y situaciones. Y esto, a pesar de las advertencias acerca de la suplantación de identidad y la acción de los "hackers". Pero, a la vez que permite el establecimiento de relaciones "virtuales" entre humanos, internet representa una fuente igualmente poderosa para la comisión de delitos y difusión de informaciones falsas. Y no existe, hasta el momento, una educación adecuada para el manejo de las informaciones y productos que ofrece internet $y$, en nuestros días, ha quedado muy claro que entre "información" y "conocimiento" existe un vacío y que suponer que ambos conceptos se solapan representa un grave error que se está comenzando a pagar claro en cuanto aparición de sesgos de pensamiento, racionalidad y capacidad de análisis de un problema desde diversas perspectivas, jerarquizadas en cuanto a lógica y no a apariencia de verdad apoyada por imágenes que pueden ser falsas.

Un tercer elemento que se ha incorporado a los instrumentos de uso cotidiano en los países avanzados (y no tanto, como el nuestro), es el teléfono móvil, que en la actualidad es un ordenador miniaturizado, con todas las posibilidades de información y comunicación del ordenador personal $y$, además, que permite establecer fácilmente comunicación visual y auditiva con cualquier otro usuario que posea un aparato de igual potencia. Se transmite mucha información de todo tipo, y representa un elemento tan frecuente que resulta frecuente encontrarse por la calle o incluso conduciendo un coche (pese a la prohibición al respecto) a personas que están utilizando su móvil mientras caminan o conducen, informaciones que son fácilmente localizables y que si son íntimas o personales, representan filtraciones y amenazas a la intimidad personal. Parece claro que capacidad de información y difusión va en detrimento claro de la intimidad, uno de los valores y metas que ha caracterizado a la sociedad moderna.

\section{iii. La ciencia: la fe en el progreso}

Una reflexión más acerca de la ciencia: gracias a la difusión y aplicaciones de la ciencia, el ciudadano de los países avanzados tiene una creencia bastante firme en que la ciencia avanza en línea recta y deposita su fe en que sus problemas más importantes van a ser resueltos por la ciencia. Concibe la ciencia como un proceso acumulativo de conocimientos "útiles" para la solución de sus problemas físicos. Formaría parte del sistema de creencias en las que se asume que el mundo sigue un progreso linear y acumulativo, lo que en definitiva representa la idea de progreso.

No siempre ha existido esta linealidad. En el mundo griego se asumía fundamentalmente una creencia en la circularidad de manera que la humanidad y el propio mundo vendrían a recrearse cada cierto período de tiempo. La idea de progreso va tomando fuerza con la Edad Moderna y representa uno de los pilares sobre los que se asienta la llustración.

El análisis histórico de la creación de la ciencia contemporánea sugiere, sin embargo, que el progreso se asemeja más a un helicoide que, aunque progresivo, va a saltos y no siempre se descubre lo que se desea. $Y$ ese progreso no se da por igual en todos los dominios del conocimiento científico, ni se conocen los parámetros que rigen y determinan el progreso científico (lo más desconocido en ciencia es el proceso 
de creatividad). Esto no significa una devaluación de la ciencia sino una puesta en razón y establecimiento de limitaciones a la idea de progreso lineal aplicada al desarrollo científico. Y, por lo que se refiere a las aplicaciones sociales de la ciencia, una afirmación realista acerca de las exacerbadas expectativas que existen incluso dentro de ciertos círculos científicos.

\section{g. La psicología como una de las "ciencias del hombre"}

La psicología como ciencia es uno de los productos obtenidos de los intentos acelerados por el renacimiento y acentuados por la Ilustración de la creación de las "ciencias del hombre", frente al esfuerzo medieval por generar una ciencia de Dios ${ }^{11}$. Es verdad, sin embargo, que este movimiento ya está presente

11 Hasta ahora se ha estado utilizando la expresión de "ciencia" con una única significación, aplicable al estudio de todos los fenómenos (físicos, biológicos, psicológicos, sociales, históricos) y, en todo caso se aplican unas modulaciones específicas para poder estudiar con el máximo rigor posible los fenómenos. Sucede que esa tradición de "ciencias del hombre" llevó a la formulación de Windelband de dos tipos de ciencia: las ciencias de la naturaleza ( las Naturwissenschaften, específica de la física, química e incluso la biología) y las ciencias del espíritu (las Geistes -wissenschaften, con métodos específicos para el estudio de fenómenos humanos y dedicadas más que a explicar los fenómenos, a comprenderlos y darles sentido en un contexto de significado, y esa era la acepción aplicable a la psicología, la economía, la sociología y la historia, por ejemplo). Esta diferenciación, de una u otra forma, se ha estado manteniendo hasta nuestros días, si bien se ha modificado el vocabulario y los procedimientos a seguir. A pesar de esta diferenciación, la corriente principal de pensamiento se ha decantado por una "conversión" del estudio de las ciencias del hombre como ciencias naturales, lo que ha dado muchos resultados, aunque no todos relevantes, ni aceptados por toda la comunidad académica. Y el problema sigue planteado, aunque sin soluciones definitivas (ni siquiera consensuadas por todos los académicos): hay dominios científicos que son más susceptibles que otros para el análisis naturalista (como las relaciones psicofísicas) y otras que se resisten considerablemente a ese reduccionismo (como el análisis de las vivencias del ser humano). En este sentido el proyecto de creación de unas "ciencias del hombre" se encuentra, en nuestros días, en proyecto, con unos tímidos avances sobre el mecanicismo y materialismo de base que intenta reducir todo a expresiones numéricas sobre códigos algo más que discutibles. en el pensamiento occidental desde la época clásica del pensamiento griego, pero su relevancia dentro de la evolución histórica medieval era pequeña, y que fue reflotada en el siglo XVIII por la Ilustración. En este esfuerzo de laicización del conocimienque convirtió la base y meta de la motivación humana individual y social en el logro de la felicidad ${ }^{12}$, en lo que coincidían empiristas ingleses, utilitaristas y positivistas (en una parte considerable de los intereses se decantaba el logro de la felicidad con el logro y disfrute de bienes materiales, lo que reorientó los esfuerzos hacia el logro de un bienestar material).

Todavía es posible asumir en nuestros días, la influencia de la "Ilustración", en el siglo XVIII, como un movimiento potente que orientó el análisis de la realidad sociocultural en Europa Occidental hacia actitudes racio-empíricas laicas y en donde la contrastación de las afirmaciones tendía a proponerse como la correspondencia entre las afirmaciones realizadas y la realidad externa y a lo que se acompañó de una fuerte tendencia a modificar el mundo social (la Revolución Francesa, por ejemplo, aunque no es el único movimiento).

De una u otra forma, los tres lemas que representaron motivaciones principales resumidoras de cambio siguen presentes, aunque su

12. Posiblemente la historia de la psicología debería ser modulada en función de esta idea de la ilustración. Esta sensibilidad fue transformada después de la Segunda Guerra en el siglo XX y como consecuencia de los efectos de la misma guerra sobre las personas. Se generó una psicología clínica, progresivamente más poderosa y que llegó a convertir a gran parte de la psicología en una especialidad de ciencias de la salud que acentuó el estudio de la disminución del sufrimiento (lo que forma parte de la psicología), pero también a costa de soslayar o disminuir significativamente la investigación y trabajos acerca de la búsqueda de bienestar y/o felicidad. A ello ayudó considerablemente la primacía del materialismo y la identificación de bienestar con riqueza y posesión de bienes materiales. 
significación se ha modificado: libertad, igualdad y fraternidad. Para algunos teóricos somos "hijos de la llustración" o, cuanto menos, hijastros que hemos refundido y reconceptualizado los lemas, incluso se ha completado con alguno más, aunque sustancialmente siguen funcionando como valores ideales a conseguir.

Desde esta perspectiva la "psicología positiva", promovida como una de las últimas novedades, no representa una novedad sino la toma en consideración de ese proyecto que no se realizó hasta ahora de la psicología como una de las ciencias del hombre. El problema es que la principal derivación de esa meta ha sido primar ante todo el bienestar material (la economía) y, antes de convertirse en ciencia plena ha derivado en objetivo único del funcionamiento social y, por ello, en dogma.

El caso es que ese desarrollismo económico representa una base muy poderosa de sustentación del sistema social a sabiendas de que no representa un elemento aislado. Los datos existentes (Estados Unidos, en España no existen datos al respecto) muestran que la sensación de bienestar personal de los ciudadanos desde 1920 al 2000 se ha mantenido prácticamente constante, a pesar de que el progreso material ha sido muy significativo.

En los comienzos del siglo XXI se han podido contemplar fenómenos relevantes, complejos y no especialmente satisfactorios para la mayoría de los ciudadanos. La aparición de sucesos insatisfactorios es algo frecuente, aunque la intensidad y duración de los que nos siguen sucediendo está provocando otros, que pueden llevar a asumir que anuncian el fin de una época, de una manera de vivir y hasta de modos de pensar y sentir que estaban presentes hace poco menos de cuatro décadas.

En muchos países, incluido el nuestro, se generó una crisis económica que echó al traste el sueño de la "sociedad del bienestar" como un estado generalizado para toda (o la mayor parte) de la población, a lo que se acompañaban un conjunto de bienes y mejoras sociales. No es la primera crisis, ni desgraciadamente, va a ser la última. Pero está siendo especialmente dura para sectores de la población que antes de ella eran ciudadanos "normales", "normalmente adaptados" y desempeñaban su trabajo sin problemas. $Y$ han convertido a la mayor parte de la población en un tipo de personas que perciben el trabajo como una recompensa, su estado económico como preocupante, cuando no desastroso y han ayudado al deterioro de las relaciones personales tal y como eran entendidas y practicadas hace unos años. Complementariamente ha transformado a ciertos profesionales (y especialmente a muchos periodistas) en "economistas" que dictan sentencias acerca de lo que está sucediendo y cómo salir de esta crisis, con una sensación de infalibilidad mayor que la del papa de Roma respecto a los dogmas de la Iglesia.

De una u otra forma, todas las crisis se superan, aunque el precio que hay que pagar es, cada vez, más grande. Y... pasados unos años, vuelven. Existe una fundada esperanza de que la actual se supere también, aunque la salida de la misma va a representar, muy posiblemente, la gestación de nuevas formas de relaciones sociales y personales, junto con unos cambios en la estructura y en la dinámica social. Y eso puede querer decir que la actual "crisis econó- 
mica" no es solamente económica y que están coincidiendo con ella cambios tecnológicos, sociales y personales que llevan consigo sus propias "crisis" (o dicho de otra manera, cambios que no son previsibles y para los cuales existe un nivel de tolerancia o de adaptación, pero que no es infinito $y$, desgraciadamente, ha habido cambios básicos que han sido demasiado rápidos unos o demasiado radicales otros, de lo que nos hemos ocupado en las páginas anteriores).

No se conocen los determinantes que promueven este tipo de crisis $y$, posiblemente, de ningún otro tipo. Existen muchas teorías, o mejor, hipótesis teóricas, aunque ninguna contrastación, más allá de afirmaciones de sentido común ${ }^{13}$, aunque sí está clara su existencia y recurrencia. Se sabe que, usualmente, para su superación se exigen muchos sacrificios por parte de un gran sector de la población y que sale beneficiado otro sector, mucho más minoritario, que se convierten o en nuevos ricos, o en más ricos de lo que lo eran con anterioridad.

Aunque sin ninguna seguridad al respecto, es muy posible pensar que esas crisis se encuentran pre-determinadas por el propio sistema económico y social (son cíclicas e inherentes al sistema), así como por los errores y abusos de personas y organizaciones que se mueven a la búsqueda del propio beneficio y lucro sin consideración alguna hacia los de-

13 Entre otras cosas se identifica la economía "macro", con la "micro", cuando la situación en que vivimos es una clara demostración de que ambas funcionan con leyes y normas distintas. Y las causas de estas crisis se sustentan en afirmaciones tales como: "aparecen cuando se gasta más de lo que se ingresa", aunque asimismo aparecen problemas económicos en el caso contrario (de ingresar mucho más de lo que se gasta, o simplemente, disminución considerable del gasto inmovilizando la mayor parte de los ingresos), sin que estas últimas afirmaciones formen parte del discurso al uso. más. En la medida en que la sociedad implica la interacción entre sistemas y personas-organizaciones, no cabe una solución definitiva dentro del sistema, ni soluciones de ingeniería sin participación de personas (las "soluciones" legales, al margen o independientemente de las personas, son una quimera porque es la interacción entre personas y sistemas lo que determina la realidad, y no el aparato legal). Y tampoco tenemos un sistema de "recambio" que impida la aparición de este tipo de problemas, aunque caben soluciones de compromiso que puedan aliviar el problema. $Y$ entre estas soluciones se debe contar con el individuo, un individuo un tanto distinto a aquél que busca, prioritariamente, la eficacia y la economía saneada, que tolere la ambigüedad y la inestabilidad en muchas de las situaciones de la vida, tome en consideración a sus congéneres y pueda vivir y dejar vivir a los demás, lo que implicaría un cambio importante en el sistema educativo total e incluso más de un reajuste respecto al sistema de valores actuantes en nuestro entorno social. Estas notas, junto a la sensibilidad hacia los problemas personales y sociales forman parte del entramado conceptual de la personalidad de las personas sabias. A lo que debería añadirse la promoción de una actividad cognitiva en la que se tomen en cuenta los problemas personales de uno/a mismo/a y de los demás y sus maneras reales o realistas de resolverlos.

En la medida en que se asuma que se trata solamente de una crisis "económica", las soluciones más adecuadas se deberían centrar y promover soluciones económicas o que se restrinjan al ámbito económico. Aunque, en estas 
situaciones se reconceptualiza la misma dinámica social a partir de tesis marxistas en las que la economía determina el funcionamiento social y hasta la cultura. Nada se "escapa" a las crisis económicas. Y, posiblemente esto es lo que justificaría el tipo de propuestas que son muy frecuentes en nuestros días en el sentido de incrementar la "competitividad", identificada como eficacia productiva. La sociedad (y sus miembros) alcanzarían el bienestar social tan solo si son "competitivos", lo que viene a significar que puedan producirse productos de calidad a bajo precio, lo más barato posible, lo que se traduce como mayor volumen de trabajo por el mismo salario o incluso por un salario menor (la solución de mayor competitividad a base de mayor salario se considera que ya ha fracasado, entre otras cosas, porque iría en contra de convicciones muy firmemente aceptadas como "verdades" absolutas). Y, además, "todo el resto permanecería igual"14. Esto es: se promueve un análisis muy parcial, que deja intacto al sistema y que prescribe cambios en el papel de las personas. Da la impresión de que, o bien el sistema se considera intocable (prácticamente perfecto y por ello mismo, inmejorable), o bien el sistema se considera como "lo menos malo", por lo que, asimismo, debe mantenerse tal y como está, con unos pocos cambios cosméticos... para volver a la "sociedad del bienestar".

14 El problema, con toda claridad, no se resuelve de esa manera, entre otras cosas porque se puede llegar a un incremento de productividad del $200 \%$ y, si esta producción no se vende, si no se diluye en el mundo del mercado... para nada se ha producido. Y la entrada en el mercado "con éxito" quiere decir que se debe comprar y vender, para lo que se exige la existencia de recursos económicos por parte de los compradores.
Para bien o para mal, parece que es verdad que la economía influye y hasta determina sectores del funcionamiento personal y social. Aunque también es verdad que resulta un sector parcial y cuya importancia es más "atribuida" políticamente, que realmente demostrada. Un ejemplo muy antiguo, dentro de la mitología, se refiere al rey Midas, que todo lo que tocaba se convertía en oro (por lo que no había problemas económicos en su vida personal ni en su reino: bastaría con que él tocara aquello que deseara convertir en oro). Pero, a la vez, nadie podía tener contacto físico con Midas (ni su familia), porque se convertía, asimismo, en oro. La conversión de todo en "riqueza" económica, llevada a su extremo, lleva a la desaparición de las personas.

Existen algunos problemas más con este tipo de planteamiento. En primer lugar, desde hace más de medio siglo, muchos países se encuentran comprometidos con un incremento en productividad través de reformas educativas encaminadas a una mayor cualificación científica y profesional, lo que no ha impedido la aparición de crisis, antes al contrario. En segundo lugar, la "profesionalización" y progresiva especialización de conocimientos no ha traído consigo solamente unos cambios en el currículo vital de los ciudadanos, sino que, además, ha venido acompañado de una delincuencia económica de una frecuencia excesiva incluso para sociedades como la nuestra. En tercer lugar, los "poderes fácticos" han dificultado sobremanera la realización de estudios científicos acerca de la aparición y dinámica de estas crisis (la dificultad en la obtención de información es notoria, así como la carencia de 
fondos para la investigación de estos fenómenos) por lo que abundan las "opiniones" y argumentos "racionalmente plausibles" aunque sin contrastar, preñados de carga ideológica. Y, para no abundar más en el tema, la aparición de la corrupción casi generalizada y el tipo de personas con ella comprometida ha generado una considerable desconfianza en el funcionamiento de las instituciones de control social de la economía y la sospecha de que con mayor competitividad se lograría una mayor frecuencia de un tipo de ser humano antisocial y promotor de mayores desajustes sociales.

Se acaba de escribir que en los últimos 50 años muchos gobiernos se han esforzado por incrementar la competitividad mediante una serie de reformas educativas que han promovido la educación generalizada para toda la población y el denominado "efecto Flynt", con la detección de un incremento en el cociente intelectual de la población. Ese incremento, sin embargo, no ha traído consigo una mejora significativa del bienestar social. "Objetivamente" se ha modificado sustancialmente la vida cotidiana con la aplicación de los avances científicos y tecnológicos al mundo socio-personal, pero la valoración del bienestar personal por parte de los ciudadanos, apenas se ha cambiado, y cuando lo ha hecho, no siempre ha sido en el sentido de un mayor bienestar personal.

Es muy posible que todo ello sea debido a que las "crisis económicas" no sean solamente económicas sino que sean no una causa sino una consecuencia del sistema total y que, a la base de ellas se encuentren problemas de conceptuación y estrategias de intervención social, así como sistemas de valores un tanto contradictorios $\mathrm{O}$, al menos, incoherentes hasta el punto de que puedan generarse estilos de vida socialmente aceptados y que van en detrimento de los intereses de la población (los ciudadanos) en general, o de la mayor parte de ella.

Aunque se es consciente de que la realidad es compleja, los modelos y esquemas que socialmente funcionan y tienden a ser aceptados por los ciudadanos son modelos y esquemas simples del estilo "A mayor trabajo, mayor salario", "Primero la obligación, y después la devoción" o la división de códigos personales y profesionales como en "Es una cuestión profesional, no es nada personal" $y$, con ella, una persona puede desahuciar a otra de la única habitación o propiedad que posee para vivir, o dejarla sin los recursos económicos y sociales (hasta de la propia vida).

Posiblemente una de las razones por las que se aceptan estos modelos simples es porque tienden a presentarse como "coherentes", su "validez" es percibida directamente, se asume que son "verdades evidentes", asumidas socialmente de forma acrítica. O, alternativamente, que estas formulaciones formarían parte del sistema de creencias nuclear o central de nuestra tradición histórica y cultural y, por ello, tendemos a asentir sobre ellas de manera automática y sin pensar. Eso no quiere decir que sean verdades inviolables.

Una de las secuelas que ha traído consigo esta crisis que nos inunda es que para el sistema social que tenemos, la economía representa un importante basamento, pero que dados los escasos conocimientos científicos contrastados, resulta fuente casi indetectable 
de delincuencia y, además, resulta insuficiente para el logro de un sistema social, al menos, satisfactorio para la mayoría de los ciudadanos. Otra secuela es que la eficacia y la competitividad, siendo relevantes, no resultan suficientes para el logro de ese bienestar sociopersonal (entre otras cosas porque eficacia, eficiencia y competencia no siempre van unidas al éxito social).

El sistema que ha convertido al ser humano en número estadístico ha estado ignorando aspectos de ese ser humano que son esenciales, como la convivencia, la honestidad, la tolerancia de situaciones ambiguas y vivir sin violencia, junto al cultivo de aspectos afectivos como la compasión, el amor y el altruismo. Y precisamente, estos aspectos se relacionan estrechamente no con la inteligencia sino con la sabiduría. De ahí la necesidad de incorporar la sabiduría al sistema educativo, productivo, sanitario y social en general.

\section{Bibliografía}

Bauman, Z. (1993).- Post-modern ethics, Oxford, Blackwell.

Bauman, Z. (1995).- Life in fragments. Essays in post-modern morality, Oxford, Blackwell.

Inglegart, R. (1977).- The silent revolution. Changing values and political styles among western publics, Princeton, NJ, Princeton University Press.

Inglehart, R. (1990).- Cultural shift in advanced industrial society, Princeton, NJ, Princeton University Press.

Inglehart, R. (1991).- Thrust between nations. Primordial ties, societal learnig and economic development. En K. Reif \& R. Inglehart (eds.).-Eurobarometer, New York, McMillan.

Kendler, H. H. (1999).- The role of value in a world of Psychology, American Psychologist, 54, 828-835.

Lyotard, J. F. (1979).- La conditions post-moder- ne. Rapport sur le savoir, Paris, Editions de Minuit.

Lyotard, J. F. (1983).- Le différend, Paris, Editions de Minuit. 